\title{
Carcinosarcoma of the cervix uteri
}

INSERM

\section{Source}

INSERM. (1999). Orphanet: an online rare disease and orphan drug data base.

Carcinosarcoma of the cervix uteri. ORPHA:213787

Carcinosarcoma of the cervix uteri is a rare, malignant, mixed epithelial and mesenchymal tumor, located in the cervix uteri, composed of an admixture of carcinomatous and sarcomatous elements. It usually presents with abnormal vaginal bleeding and a round, well-defined, grey to yellowish-white, pedunculated polypoid mass protruding through the cervical canal. Association with HPV infection (especially serotype 16) has been frequently reported. 